\title{
ВЗАЄМОЗВ'ЯЗКИ МІЖ ПАРАМЕТРАМИ ВНУТРІШНЬОСЕРЦЕВОЇ ГЕМОДИНАМІКИ У ДІТЕЙ ІЗ ДВОСТУЛКОВИМ АОРТАЛЬНИМ КЛАПАНОМ СЕРЦЯ ПРИ ДИНАМІЧНОМУ СПОСТЕРЕЖЕННІ
}

\begin{abstract}
Резюме. Діти з двостулковим аортальним клапаном (ДАК) серця потребують динамічного спостереження у зв'язку з поступовим розвитком в них порушень внтрішньосерцевої гемодинаміки та подальшим розвитком серйозних ускладнень, таких, як порушення функції лівого шлуночка, міокардіальна гіпертрофрія та розшарування аорти.

Мета дослідження - визначити взаємозв'язки між доплерографічними параметрами та змінами внутрішньосерцевої гемодинаміки у хворих дітей із двостулковим аортальним клапаном, при динамічному спостереженні.

Матеріали і методи. У 28 дітей із двостулковим аортальним клапаном, середній вік яких склав $(10,2 \pm 0,7)$ року, без ознак серцевої недостатності проведено доплерографрічне дослідження серця у динаміці однорічного спостереження. Зіставлено отримані дані з основним доплерографічним показником та виконано кореляційний аналіз між зазначеними параметрами при першому та другому дослідженнях.

Результати досліджень та їх обговорення. Встановлено достовірне збільшення градієнта тиску на аортальному клапані та кінцевого діастолічного об'єму лівого шлуночка при повторному доплерографічному дослідженні. За даними кореляційного аналізу, при обстеженні в динаміці виявлено зникнення раніше встановлених кореляцій з боку правих камер серця та появу нових із показниками гемодинаміки на аортальному клапані.
\end{abstract}

Висновки. Визначено необхідність повторних доплерограсрічних обстежень дітей із ДАК з інтервалом в 1 рік.

Ключові слова: двостулковий аортальний клапан; діти; доплерограсрія; динамічне спостереження; праві відділи серця.

ВстУп Питання організації спостереження за дітьми з двостулковим аортальним клапаном серця (ДАК) залишаються на сьогодні досить актуальними. Це перш за все пов'язано з тим, що ДАК, як найбільш поширена вроджена вада серця (ВВС), у дитячому віці перебігає практично безсимптомно і виявляється здебільше випадково при ультразвуковому дослідженні $[1,4,5]$. Разом з тим, такі прояви цієї патології, як гіпертрофрія міокарда, розшарування аорти розвиваються поступово, а пов'язані з ними гострі серцево-судинні події розвиваються вже у дорослому віці $[2,3,7]$. Виходячи з вищенаведеного, виникає необхідність визначення ранніх змін у міокарді хворих на ДАК дітей з метою запобігання як пізніх ускладнень цієї ВВС, так й ефективного планування її хірургічної корекції. Необхідно також зазначити, що визначення доплерографічних критеріїв ранніх змін у зазначеній когорті хворих дітей також $€$ актуальним з приводу визначення частоти проведення в них ультразвукової діагностики серця.

Метою дослідження було визначення взаємозв'язків між доплерографічними параметрами, які найбільш щільно пов'язані з розвитком ранніх змін внутрішньосерцевої гемодинаміки у хворих дітей із ДАК в динаміці однорічного спостереження, що може мати важливе предикативне значення $з$ точки зору подальшого спостереження та розвитку подальших серцево-судинних ускладнень у цієі категорії хворих дітей.

МАТЕРІАЛИ І МЕТОДИ За Допомогою сканера Medison - 8000 датчиком 2,5 МГц із визначенням стандартних доплерографічних параметрів було проведено дослідження у 28 дітей з ДАК. Повторно його проводили з однорічним інтервалом. У всіх хворих перший та другий доплерографічні тести виконували у тих самих умовах і на тому ж обладнанні та один спеціаліст з ультразвукової діагностики серця. Середній вік хворих при першому дослідженні склав $(10,2 \pm 0,7)$ р. Серед 28 хворих хлопчиків було 21 (75\%). У всіх пацієнтів із ДАК не було ознак серцевої недостатності та гемодинамічно значущих порушень внутрішньосерцевої гемодинаміки при першому дослідженні. Статистичну обробку даних проводили за допомогою статистичного пакета Statistica 6.0 з викорис- танням критерію Стьюдента та визначенням кореляцій за Спірменом.

Дослідження було узгоджено етичною комісією Запорізької обласної дитячої клінічної лікарні та медичного університету. У батьків хворих отримали інформовану згоду на проведення дослідження.

РЕЗУЛЬТАТИ ДОСЛІДЖЕНЬ ТА ЇХ ОБГОВОРЕННЯ На першому етапі дослідження було проведено порівняльний аналіз основних анатомічних характеристик та параметрів внутрішньосерцевої гемодинаміки у вищезазначених групах дітей. Дані наведені в таблиці.

Як видно з таблиці, більшість доплерографічних параметрів при першому та повторному обстеженнях у дітей із ДАК не змінювалася у динаміці однорічного спостереження, і розбіжності між ними не набували достовірності ( $>0,05)$. При цьому спостерігалось збільшення кінцевого діастолічного об'єму лівого шлуночка до $(63,06 \pm 4,88)$ мл проти $(47,31 \pm 5,48)$ мл $(p<0,05)$ при першому обстеженні. Слід також зазначити, що при повторному ультразвуковому дослідженні серця було також встановлено збільшення градієнта тиску на аортальному клапані у хворих дітей із ДАК, що складало $(12,78 \pm 0,33)$ мм рт. ст., разом 3 тим, як при первинному зверненні цей параметр склав $(9,91 \pm 1,83)$ мм рт. ст. відповідно $(p<0,05)$.

3 метою виявлення взаємозв'язків між зазначеними морфоорунціональними показниками внутрішньосерцевої гемодинаміки, на наступному етапі дослідження було проведено кореляційний аналіз у двох групах дітей із ДАК у динаміці однорічного спостереження. При аналізі кореляційної матриці було встановлено, що загалом 24 доплерографічних показники при першому дослідженні мали 80 достовірних кореляцій, при цьому при повторному дослідженні кількість зазначених кореляцій зменшувалася до 54. У зв'язку з цим було проведено зіставлення отриманих кореляційних коефіцієнтів при першому і другому доплерографрічних дослідженнях. Порівняльні дані для кореляційних коефріцієнтів 3 діаметром аорти наведені на рисунку 1.

Як можна побачити з рисунку 1, кореляції з діаметром аорти та легеневої артерії були достовірними як при першому, так і при другому обстеженнях зі значеннями 
Таблиця. Морфофункціональні показники доплерехокардіографії у дітей із дАК при першому дослідженні й однорічному динамічному спостереженні (друге дослідження)

\begin{tabular}{|l|c|c|}
\hline \multicolumn{1}{|c|}{ Доплерограсрічний параметр } & Перше дослідження & Друге дослідження \\
\cline { 2 - 3 } & \multicolumn{2}{|c|}{ M \pm m } \\
\hline ЛА (діаметр легеневої артерії) (мм) & $16,58 \pm 0,94$ & $18,15 \pm 0,98$ \\
\hline Ао (діаметр аорти) (мм) & $16,70 \pm 0,93$ & $18,26 \pm 0,97$ \\
\hline Подовжений розмір лівого передсердя (мм) & $25,66 \pm 1,44$ & $26,44 \pm 1,34$ \\
\hline Поперечний розмір лівого передсердя (мм) & $22,89 \pm 1,38$ & $23,87 \pm 1,23$ \\
\hline Подовжений розмір правого передсердя (мм) & $26,22 \pm 1,26$ & $27,44 \pm 1,64$ \\
\hline Поперечний розмір правого передсердя (мм) & $25,26 \pm 1,29$ & $24,41 \pm 1,28$ \\
\hline Подовжений розмір правого шлуночка (мм) & $39,05 \pm 1,83$ & $40,19 \pm 2,03$ \\
\hline Поперечний розмір правого шлуночка (мм) & $22,21 \pm 1,24$ & $22,88 \pm 1,09$ \\
\hline ЛШ КДР (кінцевий діастолічний розмір лівого шлуночка) (мм) & $36,43 \pm 1,54$ & $37,86 \pm 1,44$ \\
\hline ЛШ КСР (кінцевий систолічний розмір лівого шлуночка) (мм) & $23,83 \pm 1,46$ & $22,45 \pm 1,19$ \\
\hline ЛШ КДО (кінцевий діастолічний об'єм лівого шлуночка) (мл) & $47,31 \pm 5,48 *$ & $63,06 \pm 4,88$ \\
\hline ЛШ КСО (кінцевий систолічний об'єм лівого шлуночка) (мм) & $16,41 \pm 2,16$ & $16,57 \pm 1,71$ \\
\hline ЛШ УО (ударний об'єм лівого шлуночка) (мл) & $39,06 \pm 4,61$ & $43,38 \pm 3,94$ \\
\hline ЛШ ФВ (фрракція викиду лівого шлуночка) (\%) & $71,16 \pm 1,45$ & $72,0 \pm 1,11$ \\
\hline МшП (товщина міжшлуночкової перетинки) & $6,65 \pm 0,22$ & $6,86 \pm 0,31$ \\
\hline ЗСлШ (товщина задньої стінки лівого шлуночка) & $6,65 \pm 0,24$ & $6,64 \pm 0,41$ \\
\hline МКшв.(пікова швидкість кровотоку на мітральному клапані) (м/с) & $0,88 \pm 0,03$ & $0,89 \pm 0,06$ \\
\hline МКгр. (піковий градієнт тиску на мітральному клапані) & $2,60 \pm 0,36$ & $2,58 \pm 0,45$ \\
\hline АоКшв.(пікова швидкість кровотоку на аортальному клапані) (м/с) & $1,44 \pm 0,14$ & $1,59 \pm 0,19$ \\
\hline АоКгр. (піковий градієнт тиску на аортальному клапані) (мм рт. ст.) & $9,91 \pm 1,83^{*}$ & $12,78 \pm 0,33$ \\
\hline ТкКшв. (пікова швидкість кровотоку на трикуспідальному клапані) (м/с) & $0,66 \pm 0,04$ & $0,67 \pm 0,04$ \\
\hline ТкКгр. (піковий градієнт тиску на трикуспідальному клапані) (мм рт. ст.) & $1,51 \pm 0,21$ & $1,36 \pm 0,23$ \\
\hline КЛАшв. (пікова швидкість кровотоку на клапані легеневої артерії) (м/с) & $0,92 \pm 0,05$ & $1,02 \pm 0,13$ \\
\hline КЛАгр. (піковий градієнт тиску на клапані легеневої артерії) (мм рт. ст.) & $3,54 \pm 0,27$ & $3,64 \pm 0,23$ \\
\hline
\end{tabular}

Примітка. $p<0,05$

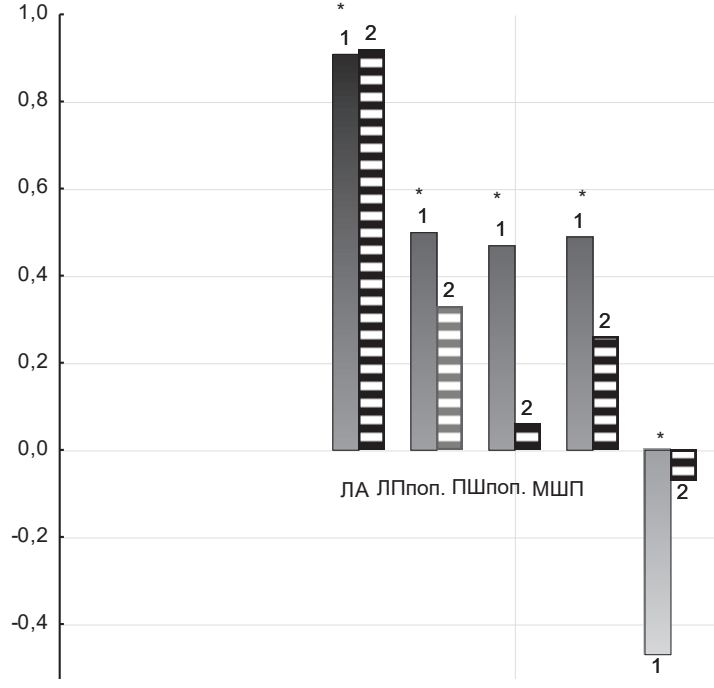

Рис. 1. Коефріцієнти кореляції (R), отримані між діаметром аорти та основними доплерографічними показниками у дітей із ДАК при першому та другому обстеженнях.

Примітки: 1) Ла - діаметр легеневої артерії; лПпоп. - поперековий розмір лівого передсердя; ПШпоп. - поперечний розмір правого шлуночка; МшП - товщина міжшлуночкової перетинки; ТкКгр. градієнт тиску на трикуспідальному клапані;

2) * $-p<0,05$;

3) 1 - перше дослідження;

4) 2 - друге дослідження

коесріцієнтів 0,91 $(p<0,05)$ та 0,92 $(p<0,05)$. Разом 3 тим, відповідні кореляції з поперековим розміром лівого перед- сердя втрачали достовірність при другому обстеженні $(R=0,50 ; p<0,05$ та $R=0,33 ; p>0,05$ відповідно). Подібна тенденція також мала місце для кореляції із поперечним розміром правого шлуночка $(R=0,47 ; p<0,05$ та $R=0,06$; $\mathrm{p}>0,05$ відповідно), міжшлуночкової перетинки $(R=0,49$; $\mathrm{p}<0,05$ та $\mathrm{R}=0,26 ; \mathrm{p}>0,05$ відповідно), а також градієнта тиску на трикуспідальному клапані $(R=-0,47 ; p<0,05$ та $\mathrm{R}=-0,07 ; \mathrm{p}>0,05$ відповідно).

Кореляційні коефріцієнти з подовженим розміром лівого передсердя, отримані у дітей із ДАК, при поступових обстеженнях 3 однорічним інтервалом наведено на рисунку 2.

Як можна побачити з рисунку 2, подовжений розмір лівого передсердя у дітей із ДАК мав достовірні позитивні кореляції як при першому, так й при другому обстеженнях 3 подовженим розміром правого передсердя $(\mathrm{R}=0,85 ; \mathrm{p}<0,05$ та $\mathrm{R}=0,87 ; \mathrm{p}<0,05$ відповідно), а також 3 його поперечним розміром ( $R=0,68 ; p<0,05$ та $R=0,83 ; p<0,05$ відповідно). Кореляції при другому обстеженні втрачали значущість із поперечним розміром правого шлуночка $(R=0,52 ; p<0,05$ та $\mathrm{R}=0,25 ; \mathrm{p}>0,05$ відповідно) й градієнтом на клапані легеневої артерії ( $R=-0,50 ; p<0,05$ та $R=0,14 ; p>0,05$ відповідно). При цьому кореляція з градієнтом тиску на мітральному клапані навпаки набувала значущості в динаміці обстеження ( $R=0,16 ; p>0,05$ та $R=0,56 ; p<0,05$ відповідно).

Кореляції основних доплерограсрічних показників із поперечним розміром лівого передсердя при динамічному обстеженні дітей з ДАК наведені на рисунку 3.

Як можна побачити з рисунку 3, зазначені кореляції були достовірними та позитивними 3 поперечним розміром правого передсердя $(R=0,51 ; p<0,05$ та $R=0,41$; 


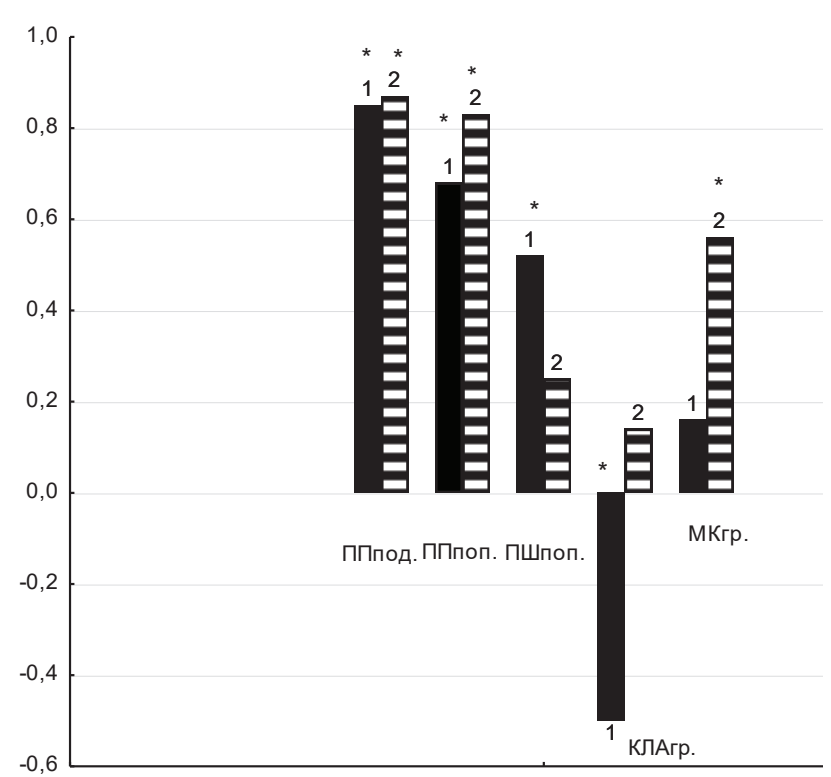

Рис. 2. Коефіцієнти кореляції (R), отримані між подовженим розміром лівого передсердя та основними доплерографічними показниками у дітей із ДАК при першому та другому обстеженнях.

Примітки: 1) ППпод. - подовжений розмір правого передсердя; ППпоп. - поперечний розмір правого передсердя; ПШпоп. - поперечний розмір правого шлуночка; КЛАгр. - градієнт тиску на клапані легеневої артерії; МКгр. - градієнт тиску на мітральному клапані;
2) * $-p<0,05$
3) 1 - перше дослідження;
4) 2 - друге дослідження.

$\mathrm{p}<0,05$ відповідно) й правого шлуночка $(\mathrm{R}=0,51 ; \mathrm{p}<0,05$ та $\mathrm{R}=0,41 ; p<0,05$ відповідно) і втрачали достовірність у динаміці обстеження з товщиною задньої стінки лівого шлуночка $(R=0,48 ; p<0,05$ та $R=0,09 ; p>0,05$ відповідно) й швидкістю кровотоку на клапані легеневої артерії ( $R=-0,51 ; p<0,05$ та $R=0,03 ; p>0,05$ відповідно).

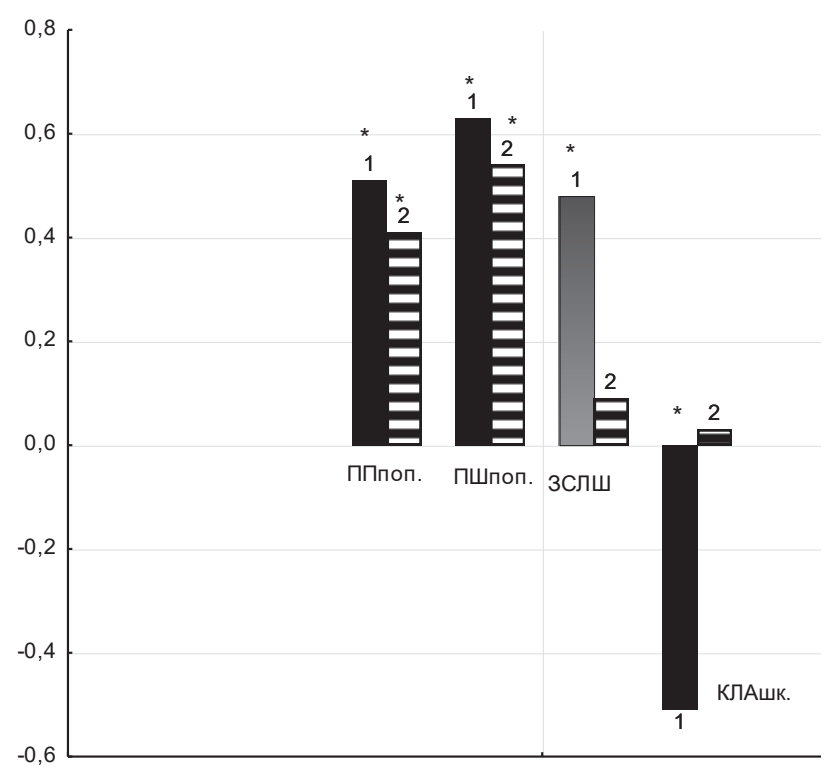

Рис. 3. Коесріцієнти кореляції (R), отримані між поперечним розміром лівого передсердя та основними доплерографічними показниками у дітей із ДАК при першому та другому обстеженнях.

Примітки: 1) ППпоп - поперечний розмір правого передсердя; ПШпоп. - поперечний розмір правого шлуночка; ЗСлШ - товщина задньої стінки лівого шлуночка; КЛАшв. - швидкість кровотоку на клапані легеневої артерії;

$$
\begin{aligned}
& \text { 2) * - р<0,05; } \\
& \text { 3) } 1 \text { - перше дослідження; } \\
& \text { 4) } 2 \text { - друге дослідження. }
\end{aligned}
$$

Кореляції, отримані з параметрами гемодинаміки на аортальному клапані, такими, як швидкість кровотоку та градієнт тиску, відображено на рисунку 4. Як можна побачити з нього, достовірні позитивні кореляції зберігались у динаміці обстеження між швидкістю кровотоку та градієнтом тиску ( $R=0,97 ;$ та $R=0,90 ; p<0,05$ відповідно), a

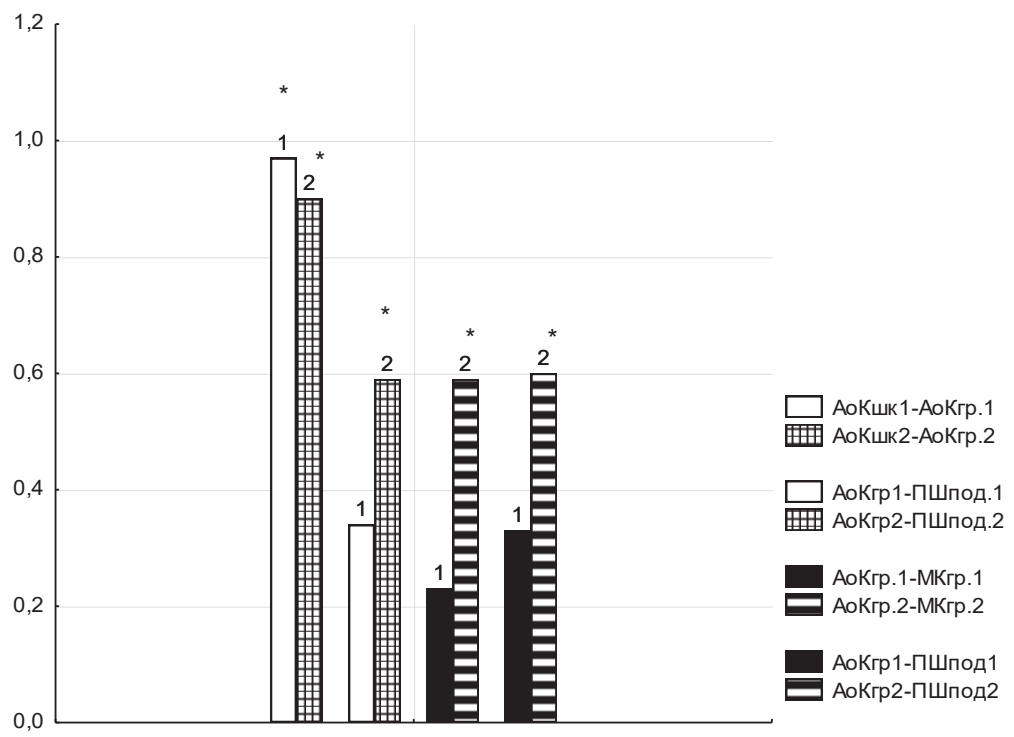

Рис. 4. Коефіцієнти кореляції (R), отримані між швидкістю кровотоку й градієнтом тиску на аортальному клапані та основними доплерографрічними показниками у дітей із ДАК при першому та другому обстеженнях.

Примітки: 1) АоКшк - швидкість кровотоку на аортальному клапані; АоКгр. - градієнт тиску на аортальному клапані; МКгр. - градієнт тиску на мітральному клапані ПШпод. - подовжений розмір правого шлуночка;

2) * $-\mathrm{p}<0,05$;

3) 1 - перше дослідження;

4) 2 - друге дослідження. 
кореляція з подовженим розміром правого шлуночка ставала значущою при другому дослідженні $(R=0,34$; $\mathrm{p}>0,05$ та $\mathrm{R}=0,59 ; \mathrm{p}<0,05$ відповідно). Така сама тенденція мала місце при наявності кореляцій градієнта тиску на клапані з подовженим розміром правого шлуночка $(\mathrm{R}=0,33 ; p>0,05$ та $\mathrm{R}=0,60 ; \mathrm{p}<0,05$ відповідно) і градієнтом тиску на мітральному клапані $(R=0,23 ; p>0,05$ та $R=0,59$; р<0,05 відповідно).

Необхідно зазначити, що тенденція до так званих зникаючих у динаміці обстеження дітей із ДАК кореляцій була також для коефіцієнтів між кінцевим систолічним розміром лівого шлуночка й поперечним розміром правого ( $\mathrm{R}=0,62 ; \mathrm{p}<0,05$ та $\mathrm{R}=-0,24 ; \mathrm{p}>0,05$ відповідно).

Таким чином, у дітей із ДАК в динаміці однорічного спостереження поряд із зростанням градієнта тиску на аортальному клапані при загальному послабленні взаємодії між різними відділами серця має місце тенденція до зменшення взаємозалежності між розмірами пере-

\section{СПИСОК ЛІТЕРАТУРИ}

1. Shamszad P. Aortic dissection in hospitalized children and young adults: a multiinstitutional study / P. Shamszad, J. N. Barnes, S. A. Morris // Congenit. Heart Dis. - 2014. - Vol. 9. - P. 54-62

2. Niwa K. Aortopathy in congenital heart disease in adults: aortic dilatation with decreased aortic elasticity that impacts negatively on left ventricular function/K. Niwa// Korean Circ. -2013. - Vol. 43. -P. 215-222.

3. Koichiro Niwa. Aortopathy / Koichiro Niwa, Harald Kaemmerer // Springer Japan KK. - 2017. - 333 p. ISBN 978-4-431-56069-2 DOI 10.1007/978-4-431-56071-5.

4. Hales A. R. Echocardiography screening of siblings of children with bicuspid aortic valve / A. R. Hales, W. T. Mahle // Pediatrics. - 2014. - Vol. 133. - P. 1212 важно правих серцевих камер та її збільшення між розмірами цих камер, та параметрами гемодинаміки на аортальному клапані

ВИсновкИ 1. В дітей, які мають ДАК у динаміці однорічного спостереження, збільшується градієнт тиску на аортальному клапані та кінцевий діастолічний об'єм лівого шлуночка.

2. У дітей із ДАК разом із гемодинамічними порушеннями на аортальному клапані відбувається рання перебудова геометрії міокарда за рахунок переважно правих відділів серця.

3. Виявлені морфофункціональні особливості при динамічному спостереженні у дітей із ДАК диктують необхідність проведення кардіальної доплерографрії не рідше, ніж один раз на рік.

Перспективою подальших досліджень $€$ продовження динамічного спостереження за дітьми з двостулковим аортальним клапаном серця та визначення груп ризику розвитку кардіальних ускладнень.
5. Evaluation of cardiovascular changes in children with BAVS / S. Hanedan Onan, A. Baykan, S. Sezer [et al.] // Pediatr. Cardiol. - 2016. - Vol. 37 (3). - P. 472-481. Epub 2015 Nov 20.

6. Relation of aortic valve morphologic characteristics to aortic valve insufficiency and residual stenosis in children with congenital aortic stenosis undergoing balloon valvuloplasty / C. J. Petit, K. Gao, B. H. Goldstein [et al.] // Am. J. Cardiol. - 2016. - Vol. 117 (6). P. 972

7. Samuel S. Bicuspid aortic valve disease / S. Samuel, K. Candice // Journal of the American College of Cardiology. - 2010. - Vol. 55 (25). - P. 2789-2800.

\section{INTERRELATIONS OF HEART HEMODYNAMICS PARAMETERS IN CHILDREN WITH BICUSPID AORTIC VALVE AT DYNAMIC OBSERVATION}

Summary. Children with bicuspid aortic valve of the heart (BAV) require dynamic observation due to the progredient heart haemodynamics disorders and serious complications development such as impairment of left ventricular function, myocardial hypertrophy and aortic dissection.

The aim of the study - to detect the relationships between heart Doppler echocardiography parameters and changes in intracardiac hemodynamics in children with BAV at their dynamic observation.

Materials and Methods. In 28 children with a bicuspid aortic valve, with an average age of $10.2 \pm 0.7$ and without the signs of heart failure, a dopplerographic examination of the heart was performed in the follow-up dynamics after 1 year. A comparison of the obtained data of the basic dopplerographic parameters and correlation analysis between mentioned parameters at 1 and 2 investigation was conducted.

Results and Discussion. A significant increase in the pressure gradient on the aortic valve as well as the end diastolic volume of the left ventricle was established at a repeat dopplerographic study. According to the correlation analysis during the follow-up examination the disappearance of previously revealed correlations with the right chambers of the heart and the appearance of new ones with hemodynamic parameters on the aortic valve were detected.

Conclusions. The necessity of repeated dopplerographic examinations in children with BAV with an 1 year interval is determined.

Key words: bicuspid aortic valve; children; doplerography; dynamic observation; right heart chambers. 


\section{ВЗАИМОСВЯЗИ МЕЖДУ ПАРАМЕТРАМИ ВНУТРИСЕРДЕЧНОЙ ГЕМОДИНАМИКИ У ДЕТЕЙ С ДВУХСТВОРЧАТЫМ АОРТАЛЬНЫМ КЛАПАНОМ СЕРДЦА ПРИ ДИНАМИЧЕСКОМ НАБЛЮДЕНИИ}

Резюме. Дети с двустворчатым аортальным клапаном (ДАК) сердца нуждаются в динамическом наблюдении в связи с постепенным развитием у них нарушений внутрисердечной гемодинамики и развитием серьезных осложнений, таких, как нарушение фрункции левого желудочка, миокардиальная гипертрофия и расслоение аорты.

Цель исследования - определить взаимосвязи между допплерографическими параметрами и изменениями внутрисердечной гемодинамики у детей с ДАК при динамическом наблюдении.

Материалы и методы. У 28 детей с двустворчатым аортальным клапаном, средний возраст которых составил (10,2士0,7) лет, без признаков сердечной недостаточности проведено допплерографическое исследование сердца в динамике наблюдения через 1 год. Сопоставлено полученные данные по основным допплерографическим показателям и корреляционный анализ между указанными параметрами при первому и второму исследованиях.

Результаты исследований и их обсуждение. Установлено достоверное увеличение градиента давления на аортальном клапане и конечного диастолического объема левого желудочка при повторном допплерографическом исследовании. По данным корреляционного анализа при обследовании в динамике обнаружено исчезновение ранее выявленых корреляций со стороны правых камер сердца и появление новых с показателями гемодинамики на аортальном клапане.

Выводы. Определена необходимость повторных допплерографических обследований детей с ДАК с интервалом в 1 год.

Ключевые слова: двустворчатый аортальный клапан; дети; допплерография; динамическое наблюдение; правые отделы сердца. 